\title{
DA LINGUAGEM ORAL À LINGUAGEM DA HIPERMÍdIA reflexões sobre cultura e formação do educador
}

\author{
Roseli Fischmann \\ Professora do Programa de Pós-Graduação em Educação da Universidade de São Paulo \\ e da Pós-Graduação da Universidade Mackenzie
}

\begin{abstract}
Resumo: Reflexões acerca de cultura e de linguagem, procurando direcioná-las à questão da formação de professores. Para isso, analisam-se resultados de duas pesquisas: uma conduzida por Betty Mindlin entre diversos grupos indígenas, publicada no livro Terra grávida; e outra, de cunho interdisciplinar, coordenada por Sérgio Bairon, publicada em linguagem de hipermídia, em CD-ROM, Hipermídia, psicanálise e história da cultura. Procura-se demonstrar como a temática das culturas se encontra subjacente à escolha do uso de diferentes linguagens para expressar diversas visões de mundo e diferentes problematizações sobre o destino humano, do oral ao para-além-da-escrita.

Palavras-chave: cultura e linguagem; formação do educador; pesquisa e ducação.
\end{abstract}

A adoção de conteúdos ligados às questões culturais na formação de educadores vem ganhando cada vez mais espaço nas propostas curriculares. Tal espaço e visibilidade são proporcionais ao avanço da construção do conhecimento no campo da educação, em suas relações com o campo da cultura.

É claro que não se pretende discutir, aqui, o percurso do conceito de cultura nas pesquisas educacionais, tarefa que extrapola o escopo deste trabalho. Contudo, é preciso lembrar, em particular, que a cada momento histórico corresponde certa abordagem do conceito de cultura, com repercussões no campo sociopolítico e, em decorrência, educacional. A produção do conhecimento acadêmico, por sua vez, ora distancia-se desse movimento dialógico, ora o repercute e, em momentos específicos, pode mesmo provocá-lo.

Um exemplo dessa teia intrincada de relações pode ser encontrado no artigo "Identidade cultural, identidade nacional no Brasil”, de Maria Isaura Pereira de Queiroz (1989). Ali existem duas análises entrelaçadas: uma que se refere às relações entre o conceito de identidade cultural e identidade nacional; e outra que é atinente à posição de cientistas sociais brasileiros comparativamente à de europeus quanto aos mesmos conceitos. Tratada desde o século XIX pelas ciências sociais no Brasil, essa temática sofreu mudanças, vinculadas tanto ao estado do conhecimento em cada época, quanto à auto-imagem que os cientistas sociais faziam de si mesmos enquanto brasileiros e do país.
Assim define Queiroz (1989:45) o ponto aonde levaram as transformações que sofreram esses conceitos: "Atualmente, quando estudiosos brasileiros falam de identidade cultural ou de identidade nacional, referem-se, pois, a noções diferentes das utilizadas por seus colegas europeus. Nos dois casos, o que há em comum é somente o fato de que ambas noções são em geral utilizadas como instrumentos para diferenciar uma cultura ou uma coletividade do conjunto das demais. Estas noções podem se tornar também armas para lutar contra qualquer perigo que ameace com o desaparecimento ou a coletividade, ou a nação. O Brasil, cuja independência não teve de ser alcançada à força, não voltou sua arma ideológica contra outras sociedades; ela foi forjada principalmente para propósitos internos. Na Europa, ao contrário, onde as guerras constituíram uma realidade constante, compuseram elas um campo apropriado para que nascessem dois conceitos diversos: um voltado para combater os inimigos exteriores, o outro se dirigindo à diferenciação interna de coletividades na totalidade nacional."

Mais complexo ainda é o trabalho de rastrear como o avanço do conhecimento nas ciências humanas e sociais relaciona-se com o campo educacional, em particular nas formas como se reflete, ou não, nas propostas de formação de educadores.

Sem pretender adentrar esse desafio, também mais amplo que os objetivos deste trabalho, vale, ainda que bre- 
vemente, lembrar o caso do tema transversal Pluralidade Cultural, dos Parâmetros Curriculares Nacionais (Brasil, 1997 e 1998) do MEC, por seus vínculos com a questão das relações entre identidade cultural e identidade nacional.

Ao introduzir como proposta de âmbito nacional a temática da valorização da diversidade, da superação da discriminação étno-culturo-racial e da crítica à desigualdade excludente, esse documento apontou a importância dos conhecimentos originários de diversos campos para sua composição e compreensão. Deixou, portanto, subentendido o caráter indispensável de uma formação substancial e diversa para os professores, o que posteriormente refletiu-se no documento Referenciais para Formação de Professores (Brasil, 1999). Ao mesmo tempo, destacou o caráter vivencial da formação específica na temática, envolvendo a convivência intencional e interessada com diversos grupos humanos. Contudo, a complexidade da presença do campo cultural na formação de professores apenas começa a se fazer presente, exigindo ainda muitos estudos por parte dos pesquisadores no campo educacional.

Assim, este artigo busca oferecer algumas reflexões que cooperem nesse sentido, tendo como proposta apresentar a contribuição de dois pesquisadores de diferentes áreas, que trabalham o conceito de cultura de formas distintas, porém com resultado semelhante em termos de sua valorização. Estes autores foram escolhidos por trazerem aportes diferenciados e complementares, oferecendo com isso material de conteúdo altamente heurístico para o campo da educação.

Os autores escolhidos e suas obras são: Betty Mindlin em sua pesquisa junto a narradores indígenas, com destaque para seu trabalho mais recente, Terra grávida; e Sergio Bairon, com a pesquisa Hipermídia, psicanálise e história da cultura, publicada em linguagem de hipermídia. Será traçada, posteriormente, uma comparação aproximativa entre ambos, apresentando, ao final, algumas reflexões voltadas para a formação do educador. Busca-se, assim, dar uma contribuição a esse campo tão complexo, cada vez mais relevante e indispensável nos estudos de educação, em geral, e da formação do educador, em particular.

\section{PERMANÊNCIA E TRANSFORMAÇÃO}

A antropóloga Betty Mindlin desenvolve há tempos um trabalho de extrema relevância. Trata-se da coleta de histórias, diretamente na fonte que são os narradores indíge- nas de diversas etnias, notadamente do norte do Brasil, fazendo, a seguir, a transposição da narrativa em linguagem oral, na maior parte das vezes nas línguas de origem, para a escrita, em Português.

Trabalho árduo, que somente tem sido possível em razão da experiência, competência acadêmica, dedicação e compromisso da pesquisadora com os indígenas. Trabalhando com diferentes grupos, vivendo o dia-a-dia das aldeias, colaborando na organização de sua defesa quando em contato com as novas levas de conquistadores da Amazônia, Betty Mindlin desenvolveu pesquisas, tanto a partir do Iamá - Instituto de Antropologia e Meio Ambiente, contando com a cooperação de outros antropólogos, como Carmen Junqueira e Mauro Leonel, quanto junto ao Instituto de Estudos Avançados da Universidade de São Paulo. Além disso, a antropóloga mantém processo de interlocução permanente com pesquisadores de outros países, marcando sua atuação por vivência e abordagem cosmopolita, assim como por valorização plena da diversidade cultural (Mindlin, 1998), em suas múltiplas, complexas e desafiantes faces.

Formada originalmente em Economia, curso no qual lecionou por algum tempo na USP e na Fundação Getúlio Vargas de São Paulo, Betty Mindlin soube tirar proveito dessa origem em sua ida para a Antropologia. De fato, o olhar acurado para a temática da exploração e a visão crítica das singularidades do processo de desenvolvimento do Brasil ${ }^{1}$ foram aspectos que colaboraram em muito para que a pesquisadora tivesse certo tipo de posicionamento em relação à temática indígena.

A marca notável desse posicionamento é o respeito pelo ser de cada indígena, pelo ser de cada grupo, ao mesmo tempo em que convivem, evidentemente justapostas em seus trabalhos, a afirmação da capacidade indígena para a autodeterminação e a certeza de que todo o apoio à identidade cultural de cada grupo é indispensável nos duros processos que o contato com a sociedade não-indígena impõe (Mindlin, 1997b). É por isso que sua presença em prol da causa indígena tem se feito, sobretudo, com os resultados de seu trabalho.

Em suas pesquisas, sempre respeitando e fortalecendo as identidades culturais dos diversos grupos indígenas com os quais trabalha, Betty Mindlin tem desenvolvido um vasto levantamento das histórias de cada um desses povos, agrupando-as, posteriormente, por temas. Ressalta-se que esses agrupamentos são apenas uma forma de sistematização, que outros critérios poderiam ser adotados para classificá-los, tal sua riqueza e diversidade. Com isso, a pesquisadora vem 
compondo um material precioso que permite aos indígenas, a um só tempo, o registro da memória e a possibilidade de compartilhar, cada qual, sua cosmologia com os demais, indígenas e não-indígenas. Como lembra Marcos Terena (1998:892): "O desenvolvimento, reivindicado em nome dos direitos humanos, tornar-se-á capenga, cremos, caso não esteja acompanhado do desenvolvimento cultural, da autoestima e de uma identidade étnica, compreensível inclusive ao mundo que nos cerca, como um código oral, legado pelos velhos aos mais jovens."

$\mathrm{Na}$ seqüência de um trabalho que já inclui Vozes da origem, Tuparis e tarupás, Moqueca de maridos, vem se juntar o magnífico Terra grávida, que será tratado aqui de maneira particular.

Seguindo, primordialmente, a tradição de Lévi-Strauss e Franz Caspar, ${ }^{2}$ as narrativas míticas recolhidas são parte da história desta Terra que há 500 anos é chamada Brasil, e que graças a essa pesquisa podem ser afinal conhecidas em português, em linguagem atraente mesmo para o leitor menos acostumado às leituras antropológicas.

Preocupada em analisar o rico material coletado, a autora de Terra grávida oferece uma introdução elucidativa para aqueles que já tenham familiaridade com esse tipo de produção. Aqui se insere, por exemplo, a análise que Mindlin faz do mito do Gavião, retomando e complementando a análise feita por Lévi-Strauss em $O$ cru e o cozido (Mindlin, 1999:27-30).

Da mesma forma, esse ensaio introdutório terá, sem dúvida, função motivadora para aqueles que pouco tenham se dedicado a essa verdadeira aventura, de mergulhar em mundos de mitos e personagens tão pouco conhecidos como presentes na construção de referências da diversidade constituinte do Brasil.

É possível avaliar a complexidade do trabalho realizado por Betty Mindlin, ao serem observados os distintos procedimentos metológicos desenvolvidos em cada um dos trabalhos citados. Em Vozes da origem, as narrativas dos Suruí foram gravadas, transcritas na língua original, mediante uma escrita fonética própria da língua Suruí desenvolvida pela pesquisadora, para serem então traduzidas para o português, com o auxílio de intérpretes complementando os próprios conhecimentos de Mindlin. Lembra a autora: "É claro que o estilo reflete minha própria maneira de escrever e com freqüência há uma espécie de tradução cultural, necessária para familiarizar o leitor com aspectos da vida indígena" (Mindlin, 1999:261).

Já o livro Tuparis e tarupás foi marcado por uma peculiaridade: os narradores Tupari falavam bem o portu- guês, sendo o trabalho da pesquisadora mais o de respeitar seu estilo e sabor, conforme suas próprias palavras.

Descrevendo o processo de pesquisa que resultou em Moqueca de maridos e Terra grávida, o qual envolveu os Suruí, Kampé, Gavião, Kanoé, Zoró, Arara, Macurap, Jabuti, Aruá, Arikapu, Ajuru e Tupari, Betty Mindlin assim registra o trabalho realizado: "Gravei, talvez, duas centenas de horas, quase sempre em língua indígena. As traduções foram feitas, não palavra por palavra, seguindo transcrições na língua, como no caso Suruí, mas por intérpretes que ouviam as narrativas ao mesmo tempo que eu (também por outros, uma segunda ou terceira vez, ao ouvirem as fitas), em geral pessoas com dons expressivos e criativos. Ao escrever as histórias, levei em conta o seu português e seu estilo e a minha própria imaginação, para transmitir o clima dos mitos. Algumas histórias, assim, têm uma certa recriação, na forma de escrever, fiel, porém, ao conteúdo, sem invenções novas" (Mindlin, 1999:262).

O livro Terra grávida, para o qual este artigo volta o olhar mais detidamente, a partir do recorte temático escolhido, reúne narrativas de sete grupos indígenas de Rondônia: Macurap, Jabuti, Aruá, Arikapu, Ajuru, Kanoé e Tupari. Como já mencionado, o ensaio introdutório não só facilita a leitura, como também possibilita perseguir, de maneira mais organizada, pistas para a compreensão da abordagem desses povos sobre temas universais, como a vida e a morte, a origem do universo, do mundo, dos seres humanos, o que é permitido, o que é proibido, o bem e o mal.

Confrontando o árduo trabalho de pesquisa, com seu resultado, Betty Mindlin declara sua respeitosa forma de recriação ou, talvez mais apropriadamente, de transcriação: ${ }^{3}$ "Procurei usar todos meus conhecimentos, em vez de ficar ao pé de uma letra que ainda não há. Isso não quer dizer que eu não tenha sido fiel tanto aos conteúdos quanto às formas - não inventei, segui um clima" (Mindlin, 1999:262).

Colocando o direito de voz como princípio e o reconhecimento dos direitos dos narradores, ${ }^{4}$ reafirma a autora: "Trata-se de um trabalho conjunto, feito por muitos contadores" (Mindlin, 1999:263). Por isso, a pesquisadora tem um cuidado notável ao traçar os perfis dos narradores indígenas, exalando carinho e afeto pela história de cada um, em uma junção preciosa de atitude científica com o mais indispensável humanismo que a construção do conhecimento está a requerer.

Do ponto de vista de contribuição à formação de educadores, torna-se subsídio singular conhecer esses narradores-pessoas, indígenas cujos nomes e sagas passam a 
ser conhecidos - e então as narrativas ganham vida própria, porque se sabe de onde vêm.

Sem dúvida, verá despertar em si sentimentos de respeito e solidariedade aquele que ler os perfis dos narradores, como Galib Pororoca Gurib Ajuru, Awüru Odete Aruá, Armando Moero Jabuti, Pacoré Marina Jabuti, Akükã Francisco Kanoé (o último de seu povo), Amamoeküb Aningui Basílio Macurap, Amonãi Manuel Tupari. Dentre todos, devido aos limites deste artigo, foi selecionado um dos perfis, que haverá de falar sobre o caráter vívido dos perfis traçados por Mindlin (1999:250): “Aratori Teresa Macurap É a viúva inconsolável de Dorodoim, mãe de Sawerô Basílio Macurap e madastra de Menkaiká Juraci Macurap. Vive na Baía das Onças, na A. I. Guaporé. Chorando de saudade, contou histórias em Macurap, traduzidas por Sawerô."

Constituem-se, ainda, em informações relevantes os dados que a autora traz sobre os povos de onde provêm as histórias e suas línguas, assim como o glossário que oferece, material riquíssimo a ser explorado tanto na formação de professores para Pluralidade Cultural, quanto na aplicação em sala de aula, nos diferentes níveis de ensino.

Observe-se que esse trabalho de Betty Mindlin, como os anteriores, complementa trabalhos de outros autores, já antes dirigidos especificamente a educadores, como os elaborados a partir do Mari/USP, que já se tornaram clássicos (Silva, 1987; Silva e Grupioni, 1995), alguns em cooperação com o MEC, além de pesquisas de mestrado e doutorado que têm trazido contribuição específica para a compreensão da temática de professores indígenas (por exemplo, Silva, 1997).

Enquanto esses trabalhos trazem informações indispensáveis para a formação dos professores que atuam no sistema de ensino brasileiro, a complementação propiciada pelas obras de Betty Mindlin tem a ver com a possibilidade de imersão dos professores, assim como de qualquer pessoa interessada, em mundos ricos e desconhecidos, que o preconceito e os interesses econômicos têm feito calar.

Para finalizar esta parte da reflexão, ressaltando ainda mais a relevância e o caráter indispensável da leitura de Terra grávida por professores e educadores em geral, é com grande honra que é aqui apresentada a carta dirigida por Lévi-Strauss a Betty Mindlin:5

"Paris, 10 de março de 2000

Cara Senhora,

Terra grávida, que a senhora houve por bem me enviar, é um complemento muito precioso de suas obras precedentes. Nessa, como nas outras, a senhora reuniu uma rica mitologia proveniente de povos sobre os quais não se possui quase nada. O conjunto forma um corpus impressionante que guarda relação com as grandes coletâneas clássicas da mitologia ameríndia. Foi muito proveitoso para mim. Com meus agradecimentos, solicito, cara Senhora, que aceite a expressão de minha respeitosa homenagem.

\section{Claude Lévi-Strauss \\ Professor Emérito \\ Collège de France"}

\section{POR UMA NOVA LINGUAGEM}

O apelo da simplicidade que há no acesso a informações via Internet tem se constituído em um caminho perverso de simplificação das potencialidades presentes nas novas tecnologias digitais. Em particular no campo da educação, tal simplificação tem trazido perspectivas de "ensino a distância", que são saudadas como "o" potencial por excelência dessas tecnologias no campo da educação.

Ainda que valorizando as potencialidades comunicativas presentes na Internet como mídia interativa, é necessário superar essa visão, quando se trata de ampliar o horizonte de reflexão e, portanto, de compreensão do alcance, dos limites e das possibilidades das tecnologias digitais como campo de construção de conhecimento, portanto com reflexos diretos na educação. Daí, o caminho é buscar o que se tem produzido de pesquisa nesse campo. Contudo, não-pesquisas escritas, que só fazem repetir a lógica argumentativa da linguagem verbal racional, mas sim aquelas que tragam a possibilidade de vivenciar seus caminhos, provar as marcas que sofreram, partilhar o sentido e a prática da autoria.

É por isso que este artigo trata da obra Hipermídia, psicanálise e história da cultura, de Sérgio Bairon ${ }^{6}$ (coordenador geral) e Luis Carlos Petry. Publicado em hipermídia, este trabalho rompe os limites que esta ferramenta que é aqui usada - palavras, tinta, papel - tem. Trata-se de trabalho vigoroso de pesquisa, desafiador e ousado na apresentação e na proposta. A pesquisa, seguindo a trilha acadêmica anteriormente aberta pelo coordenador, não se limitou a trabalhar conceitos, dentro dos limites habituais, porém rompeu barreiras convencionais, inserindo-se nas tendências mais avançadas da pesquisa atual 
internacional, com requintes de pioneirismo, ao também produzir, em linguagem de hipermídia, os resultados de sua investigação.

Mesmo correndo o risco de reduzir o alcance dessa obra - já que é aprisionada, aqui, regredida aos moldes convencionais - é importante o exercício de diálogo, mais que um comentário ou síntese (a qual seria mesmo impossível). Vale lembrar, em primeiro lugar, que essa obra exige uma imersão em sua proposta, não se entregando a um olhar. Trata-se de um contato passivo e ativo ao mesmo tempo. Passivo, porque, se se pretende conhecê-la, não haverá como não vivenciá-la, será necessário haver uma entrega à proposta, fruto, provavelmente, da formação psicanalítica dos autores. Ativo, porque serão os sentidos do leitor (denominação insuficiente para a relação que se estabelece nessa proposta) que guiarão o percurso.

Porém, de que caminho se trata? A referência a "método" é presente o tempo todo, na própria metáfora do labirinto. O desvelar das intenções dos autores, contudo, surge apenas quando se têm em mente suas referências filosófico-teóricas: Heiddeger, Wittgenstein, Gadamer, Lacan, Certeau (este, historiador e psicanalista lacaniano, como o coordenador).

De fato, da Hermenêutica, a obra traz soberano o conceito de jogo, conforme já trabalhado pelo coordenador em trabalho anterior: "Os jogos de linguagem apresentam a idéia de que todo encontro com ela é sempre movediço e de que faz parte do seu próprio acontecer a busca da verdade. No alemão, por exemplo, o termo Spiel (jogo, interpretação, risco, brincadeira) pretende acolher grande parte deste acontecer. Como técnica, a multimídia radicaliza e ratifica o princípio de que a linguagem tem seu verdadeiro sentido em toda ação que se converte numa modificação daquele que a experimenta. A linguagem multimidiática se apresenta como um jogo, exatamente porque, tal como este, é o 'sujeito' de si mesma. (...) Brilhantemente explorado por Johan Huizinga em Homo Ludens, a concepção de jogo assume maior responsabilidade no encontro entre a cultura e a linguagem. $\mathrm{O}$ autor apresenta o jogo como elemento fundador das funções culturais, do Direito, da Poesia, da Guerra, etc., sobretudo no sentido de impulsionar o jogador (een spelltje doen, em holandês), independentemente de ser o resultado da ação de uma consciência lógica. Esta seria, tanto em Huizinga, quanto nas propostas hermenêuticas, o principal fascínio no Spiel: jogar é, sobretudo, ser jogado. O jogo é dono dos jogadores" (Bairon, 1995:83-84).

De fato é de Gadamer (1991:149), autor que perpassa toda a reflexão e proposta metodológica do trabalho, a afirmação recorrente ao longo de Hipermídia: "todo jogar é um ser jogado". ${ }^{7}$ Essa proposta fundamenta a relação que Gadamer estabelece entre jogo e obra de arte, também fundamental para se compreender a proposta, feita por Bairon, da adoção da estética como via de compreensão: "O que teria que ser objeto de nossa reflexão não seria a consciência estética, mas a experiência da arte (...). (...) a experiência da arte não é nenhum objeto frente ao qual se encontre um sujeito que o é para si mesmo. Pelo contrário, a obra de arte tem seu verdadeiro ser no fato de que se converte em uma experiência que modifica a quem a experimenta" (Gadamer, 1991:144-145).

Na proposta de Bairon, encontram-se obras de arte trazendo o uso de diferentes linguagens como busca de compreensão universal. Lá estão fotografias amalgamadas em colagens digitais, ou então compondo telas, firmamento iluminado como no laboratório de topologia, ou trazendo a escuridão permanente por sobre o labirinto (seria o mergulho no inconsciente? No desconhecido? No que está a ser conhecido?).

Jogando (vivendo-se o "ser jogado") no labirinto, a seta do "mouse" desliza por sobre uma parede do labirinto sensibilizada, surgem imagens de Magritte, referência constante, que conduzem a outras experiências, nas quais é dada a possibilidade de sair, nas alternativas iconográficas que vão sendo desvendadas, ou ficar, e suportar a expectativa do que está por vir. O usuário/leitor/jogador encontrará animações que raptarão sua atenção, envolvendo-o em um clima impossível de controlar. Um exemplo é a sarça ardente futurista do desejo, dançando inapreensível ao som de um mantra oriental. Ou qualquer outra coisa que seja a mesma representação visual e sonora, que o leitor/jogador venha a perceber: assim será.

As citações cinematográficas, de clássicos como Tempos Modernos, Metrópolis, 2001 Uma Odisséia no Espaço, entre outros, são um exercício de pesquisa de filmes que têm profundo significado neste século que se encerra, vinculando-os a conceitos explorados pela Psicologia, pela História, pela Lingüística e pela Antropologia. Assim, ora a História da Cultura fornece os elos da interdisciplinaridade, ${ }^{8}$ ora é a arte que o faz. Já afirmara anteriormente o autor: "A livre criação daquele que produz uma obra de arte tem o potencial de abertura ao mundo, que nenhuma metodologia científica de tradição iluminista garante. A liberdade de ação imagética na arte pressupõe, em essência, uma igual liberdade de interpretação e expressão. Longe do domínio técnico 'conteudístico', a compreensão pode possibilitar um estar-no-mundo que pro- 
mova o encontro daquele que interpreta com o que é interpretado, ao ponto desta promoção revelar os horizontes envolvidos" (Bairon, 1995:199).

Vale ressaltar que as tecnologias digitais propiciam facilidades no uso dos diversos recursos propiciados pela arte, em suas diversas manifestações. Antecipando a riqueza com que exploraria esse potencial, Bairon (1995:209) afirmava em trabalho anterior: “(...) A linguagem da arte é a linguagem do não-sentido, do desapropriar-se de qualquer significado, da valorização da subjetividade, não a kantiana, mas a da polifonia bakhtiniana.

No mundo contemporâneo, vídeo, animação, colagem, efeitos, cinema, artes plásticas, etc., brigam para manterem a própria identidade institucional; mas, como vimos tudo indica que haverá uma grande hibridação dos meios de manifestação artística, a ponto de não conseguirmos mais diferenciar o espaço da arte, já que esta está cada vez mais tornando-se cotidiano."

É importante destacar que o uso de trabalhos como Hipermídia, na formação de professores, traz vantagens de várias ordens. Primeiramente, como experiência de compreensão, incorporando o cognitivo e o sensitivo, oportunidades de ampliação de horizontes. Talvez alguém indagasse - como é freqüente - de que serviria esse tipo de vivência, se for posteriormente "condenado" a trabalhar em escolas que não dispõem de facilidades da informática. Trata-se, contudo, de um modo de abordar o conhecimento, de lidar com a riqueza das produções culturais humanas, não se aprisionando nos limites do impresso em tinta e papel. Uma vez vivenciada essa formação, o professor terá condições de buscar e oferecer recursos variados a seus alunos.

Isto porque, como já foi tratado, os conceitos de jogo e estética são estruturadores da proposta analítica de Hipermídia. Há três verbos que expressam os objetivos buscados por esse trabalho em hipermídia e que estão voltados para o usuário/leitor/jogador: imergir, perguntar, projetar.

Enquanto jogo, Hipermídia convida a uma imersão, após a qual não se tem como voltar atrás. O vivido já terá alterado algo naquele que o vive, pela percepção, pelo conhecimento, ainda que inapreensível e por vezes indizível.

A profusão e riqueza de informações oferecidas anunciam, por um lado, o volume e a duração das pesquisas prévias realizadas, dentro e a partir de diferentes regionalidades científicas e artísticas. Tais pesquisas propiciaram levantamento conceitual e iconográfico ao longo de muitos anos, permitindo exploração de 30 conceitos, apre- sentados e compostos em 64 locais de interação que podem ser percorridos em diferentes níveis. ${ }^{9}$

Uma vez imerso, o leitor/usuário/jogador vê-se frente ao inesperado, ao incompreensível, instigado então a perguntar. Atividade essencialmente hermenêutica, perguntar é inevitável quando se percorre o labirinto, o qual se mostra e se esconde; oferece porém não o faz de forma simplista: provoca e, gentil, permite que se prossiga, ou não, até o limite de cada nível sucessivo de imersão. Pelo sistema de busca de palavras, pode-se pular de um conceito para outro, de uma região para outra do labirinto, assim como se tem a possibilidade de consultar, a qualquer momento, o registro dos próprios passos, pelo navegador.

O uso de técnicas atualíssimas, envolvendo cálculos e minucioso trabalho de criação digital, traz a possibilidade de girar $360^{\circ}$ em torno de diferentes objetos, ao que parece buscando operar visualmente a noção de "giro ontológico", ${ }^{10}$ propiciado pelo perguntar.

Imergir e perguntar complementam-se, como possibilidade de compreensão, no projetar. Bairon (1995:199) advertia em trabalho anterior: “(...) a compreensão deve ter presente que, tanto o comum, o peculiar, como o científico e o poético, devem ser o resultado tanto do comparativo, quanto da adivinhação. A adivinhação é imprescindível na arte como na ciência, pois jamais pode ser resultado somente da aplicação de regras."

Se é verdade que tal ação independe de suporte material, é, contudo, extremamente facilitada pela exploração hermenêutica feita pela via da linguagem da hipermídia, enquanto conjunção de diferentes linguagens e mídias, propiciada pela compatibilização operada pela digitalização. A incompletude que se manifesta a cada interação, a impotência a cada vai-e-vém, resultado do "ser jogado" (quando tudo o que se queria era jogar), levam à busca de outros conceitos, de outras experiências estéticas que projetarão o sujeito/leitor/usuário/jogador, que pouco a pouco se percebe autor.

Nesse ponto ficam evidentes os dois princípios norteadores da proposta, elaboração e produção de Hipermídia: a não-linearidade e a reticularidade.

Ao propor o não-linear como elemento de compreensão do estar-no-mundo e do permanente recolocar-se, o trabalho desafia as fronteiras das regionalidades científicas. Contudo, isto é feito com rigor e destreza, dentro da tradição proposta há tanto por Fernand Braudel - e aí fica evidente o papel da História da Cultura como elo interdisciplinar.

Ao mesmo tempo, na hipermídia está sendo analisada, a escolha a cada momento coloca-se tão atraente quanto 
difícil, como criança em frente a vitrine de doces, pois é feita uma oferta generosa de conceitos, referências estéticas, textos teóricos, notas de rodapé reflexivas, imagens pouco freqüentes de autores (seria, aí, um eco da abordagem enciclopédica do Il Seiscento, de Umberto Eco, um dos autores/obra de referência do coordenador?).

Com base nessa oferta generosa se constrói, na prática, a possibilidade de uma produtiva reticularidade que desafia o institucional na ciência e na arte. Todo aquele que se interessar poderá ter o CD-ROM à mão, para a qualquer momento navegar, experimentar novos caminhos, descobrir novas nuances das criações estéticas belíssimas, apresentadas em cores e sons, a fornecer-lhe conteúdo para ser, também, autor. O que mais poderia buscar a própria educação?

Imagens cujas texturas são revestidas de conceitos, jogos de criança, como o "jogo da velha", aplicados a conceitos extremamente complexos, trilhas musicais sensíveis, com um quê de épico por vezes, locuções instigantes que exploram as possibilidades sonoras da língua portuguesa. É a estimulação do campo perceptivo, jogando com os sentidos de uma nova e distinta maneira, que permite apenas concluir com a própria obra: "aqui está uma nova série infinita". ${ }^{11}$

\section{DO NÃO-ESCRITO AO PARA-ALÉM-DA-ESCRITA}

\author{
Como se o Mar se abrisse \\ E nos mostrasse outro Mar - \\ E este ainda - ainda outro - e os Três \\ Fossem só antecipação - \\ De Períodos de outros Mares - \\ Por Praias não visitados - \\ Estes também a Beira de Mares indevassados - \\ A Eternidade - são os Mares que virão -
}

Emily Dickinson (1999:51)

Ler Terra grávida e outros trabalhos semelhantes de Betty Mindlin é descobrir o Brasil para além da informação que é útil, porém insuficiente como proposta de encontro de alteridade - indispensável, no caso. É encontrar o vigor e beleza da diversidade, constituinte do universal. Trata-se de contribuição para transformar mentalidades construídas a partir de ensinamentos nas escolas, a tantos, por tanto tempo, que criaram um imaginário do "índio brasileiro", que, por desinteresse cultural e in- teresses de dominação, disseminaram a ignorância com relação à riqueza da diversidade brasileira. Mentalidade na qual os grupos indígenas, apesar do desaparecimento de muitos pelas políticas históricas de conquista e exploração, ainda permanecem como mais de duas centenas de grupos, falando quase o mesmo tanto de línguas.

Vale também o desafio de jogar o jogo proposto por Bairon. Estudar jogando, jogar estudando. Descobrir as trilhas das próprias possibilidades de criação, nas múltiplas formas de percorrer o labirinto e nas idas e voltas por entre os níveis. Nos caminhos do labirinto, "dar com a cara na parede" pode ser produtivo, porque permite atravessar o limite, por meio da compreensão de novos planos, com novas experiências estéticas.

Roberto Gambini, fazendo o prefácio de Tuparis $e$ tarupás, pode ser aqui invocado para auxiliar a compreensão de quão próximas são as abordagens de Betty Mindlin e Sérgio Bairon: "Os mitos revelam o fundo da alma. O fundo da alma - não da mente - é repleto de imagens incomuns, bizarras, inesperadas, que chocam e exasperam a mente consciente porque a desafiam, como a provar-lhe que aquilo que chama de realidade é apenas um arranjo temporário e artificial das coisas, que tudo é se assim parece, mas que o ser é abismal e inesgotável. A linguagem mítica - especialmente esta, brasileira, cheirando a mato, inusitada e nova, ainda que milenar - subverte a ordem das coisas, provocando releituras do mundo. Um mito contém tanta verdade sobre a natureza do real quanto a mais profunda intuição da psicologia do inconsciente. Aí reside seu valor, que ultrapassa os códigos estéticos da literatura e da arte. Um mito vale não apenas por ser belo, mas porque contém uma centelha de conhecimento roubado aos céus como o fogo de Prometeu ou da arara" (Gambini, 1993:12).

Embora o cheiro de mato possa aqui ser trocado por criação digital impactante, Lúcia Santaella, ao fazer a apresentação de Hipermídia, também explora a temática da profusão e da quebra da linearidade como fator de subversão e de compreensão: “Assim como a hipermídia como técnica permite a integração sem suturas das diferentes mídias e linguagens, isomorficamente nesta hipermídia integram-se, em cruzamentos e sobreposições, em vizinhanças e coabitações, o conceitual e o criador, o intelectual e o estético, as superfícies e palimpsestos de textos, imagens, falas e sons, estradas e sinalizações, ícones e pistas de navegação que intermitentemente lançam ao leitor piscadelas secretas para fisgá-lo nessa aventura intelectual em que pensamento e êxtase sinestésico se enlaçam" (Santaella, 2000). 
Assim também encontra-se o uso deliberado da própria imaginação, em que a criatividade transbordada é disciplinada pelos objetivos buscados: a temática do autor/ produtor (Williams, 1992) e o convite ao leitor/autor. Em Bairon (1995), eis o que propõe, como já foi visto: “A liberdade de ação imagética na arte pressupõe, em essência, uma igual liberdade de interpretação e expressão." Em Mindlin (1999:263), essa proposta também afirmase como convite: "Espero, como no caso de meus trabalhos anteriores, que as traduções sejam refeitas, com base no registro gravado que tenho nas várias línguas ou utilizando novas gravações. Conservo as gravações e as traduções de cada narrativa e de cada Narrador; minha documentação é uma espécie de museu ou arquivo para os índios ou outros pesquisadores e todo o livro pode ser reescrito por escritores índios ou outras pessoas."

A escola, como nossa civilização, tem valorizado demais o verbal e o racional. A formação de professores se afirma nessa mesma atitude, fechando um ciclo vicioso, a transmissão de certo tipo de conhecimento que se pretende linear, que se multiplica e reproduz como se fosse linear, instaurando facilmente a falta de motivação para o estudo. Acomoda-se, como analisa Bachelard (1984:167): "Chega uma altura em que o espírito gosta mais daquilo que confirma o seu saber do que daquilo que o contradiz, prefere as respostas às perguntas. Passa então a dominar o instinto conservativo e o crescimento espiritual cessa."

O conhecimento veiculado então pela escola parece esgotar-se em si, "sem utilidade", o que de certa forma é verdade, se o que se oferece arrefece qualquer vontade de conhecer mais. Como cessar a capacidade de indagar? Como romper o fluxo de interesse? Vale lembrar uma vez mais Bachelard (1984:166): “O espírito científico proibe-nos de ter uma opinião sobre questões que não compreendemos, sobre questões que não sabemos formular claramente. É preciso, antes de tudo, saber formular problemas."

A oferta de vivências estéticas polissêmicas, muitas vezes trazendo o recurso à palinódia como desafio, a possibilidade de aprofundamento por níveis, a ausência de uma estrutura que se bastaria a si, a abertura para a ação - coautoria, portanto - do leitor/jogador/navegador ao escolher, tudo isso significa, para os padrões até aqui vividos, uma mudança substancial nas possibilidades educacionais.

Do ponto de vista do desenvolvimento curricular na escola, em seus diferentes níveis, essa abordagem facilita a própria compreensão da idéia de transversalidade e da elaboração de projetos desenvolvidos em torno de temas com tal característica. Assim, a formação de professores pode incorporar esse tipo de leitura/jogo/aventura/autoria com grandes vantagens, comparativamente ao uso de meios convencionais.

O que aí se observa é a mesma escolha da possibilidade de viver mais a busca da compreensão que do conhecimento, mediante a mesma liberdade de criação, a mesma imersão no sensível para além do racional, que há na narrativa indígena, e que nesta é marcada pela simplicidade dos recursos estéticos usados. Assim, o corpo torna-se instrumento, pela voz, pelo gesto, pela expressão, com o que se garante a permanência e, ao mesmo tempo, a transformação da mensagem, a cada vez. Em Hipermídia, em meio ao percurso, reverbera-se a mesma afirmação: "Corpo é ferramenta".

O trabalho de Bairon também assemelha-se à pesquisa de Betty Mindlin na preocupação da permanência do tradicional no novo. Em suas pesquisas, Mindlin colhe mitos de narrativas orais e faz seu registro, como forma de garantir sua permanência entre os indígenas e de buscála na sociedade brasileira, divulgando-a. A passagem do oral ao escrito se faz, assim, pelo bem de ambos.

Bairon faz dialogar entre si conceitos de regionalidades científicas distintas, explorando ao longo da pesquisa o conceito de cultura, fazendo inúmeros exercícios hermenêuticos no percurso do labirinto, fundindo linguagens hoje tradicionais - escrita, fotografia, cinema, vídeo, som -, mediante as possibilidades da linguagem da hipermídia. Com isso enriquece o já existente - como as precisas citações de cinema - e explora as possibilidades heurísticas da realização da investigação conceitual com a nova ferramenta, a hipermídia.

Vale lembrar que Bachelard (1984:171), comentando características do "livro do ensino científico moderno", afirma: "Mal se lêem as primeiras páginas, vê-se que o senso comum deixa de poder falar; deixam igualmente de se ouvir as perguntas do leitor. A frase Amigo leitor seria de bom grado substituída por um aviso severo: Aluno, toma atenção! O livro põe as suas próprias questões. O livro comanda."

Esse ponto oferece possibilidades de se apresentar um dos aspectos que mais diferencia o tipo de ensino a distância que vem se fazendo e as estruturas hipermidiáticas. Com freqüência, o uso da Internet como suporte tem sido apontado como veículo preferencial dessa modalidade de ensino, beirando freqüentemente um ufanismo tecnológico, de resto já vivenciado na década de 60 com a idéia de educação pelo rádio e pela tevê e nos anos $80 \mathrm{com}$ a disseminação do vídeo. Todas essas propostas puderam 
ser incorporadas aos processos de ensino, cooperando na difusão de conhecimento. Contudo, recomenda a cautela histórica que se evite a empolgação de cunho substitutivo ("nada que não seja isso").

De fato, o que se tem visto em sua grande maioria ainda apresenta limites, seja de ordem técnica, seja de ordem conceitual. Do ponto de vista de estruturas, essa condução, que talvez poderia ser chamada de "heterocondução", freqüentemente apresenta uma lógica pronta, em que mesmo as alternativas são evidentemente limitadas. Do ponto de vista conceitual, muitas vezes repete-se, disfarçada, a estrutura linear dos livros tradicionais, pouco havendo, então, de exploração efetiva da capacidade analítica que o meio digital propicia.

Além disso, a restrição imediata de permanência na Internet, pelo acesso por assinaturas de tempo limitado, significa a submissão à lógica de mercado; mesmo nos portais gratuitos, essa lógica está presente pela exposição a mensagens de patrocinadores, os quais, por sua vez, determinam o que é, ou não, relevante.

Embora pedindo estudo específico, é interessante lembrar, por exemplo, que a divulgação massiva da Internet no Brasil como meio de comunicação, popularizando o computador como instrumento, deu-se em uma novela Explode coração (Rede Globo, 1995) ${ }^{12}$ - onde a cigana Dara trava contato, com aquele por quem se apaixonaria, em um chat. Vale observar a estratégia de marketing embutida na novela, em particular por associar a nova tecnologia ao esoterismo, pela presença cigana, com leitura do futuro através de mãos, de cartas de baralho, acentuando o estereótipo, com relação aos ciganos, e, quiçá, a ilusão de que a Internet seria algo mágico.

Não se trata, aqui, de minimizar as facilidades e possibilidades presentes na Rede. Mesmo a simples disseminação de "mensagens" em "correntes", uso entre internautas atualmente tão corriqueiro quanto envergonhado, ${ }^{13}$ pode ter um papel a cumprir, por exemplo, na descoberta maravilhada que idosos fazem da Internet como meio de comunicação, assim como solitários em geral. Ou ainda, vale lembrar as listas de discussão, originariamente praticadas em meios acadêmicos, nos primórdios da Internet, e hoje quase obrigatórias entre organizações não-governamentais e movimentos sociais (Castells, 1999).

Sem dúvida há grandes vantagens no uso e na consulta à Internet, para fins educacionais, mas ela, em si, ainda não propicia possibilidades de exploração conceitual como se observa em outros produtos digitais, como no exemplo de hipermídia aqui analisado - e aí o suporte do CD-
ROM é mais adequado, por permitir sua exploração com maior liberdade, sem as pressões presentes quando se marca, como se faz no Brasil, a duração da consulta pelo "tempo conectado".

Os autores aqui estudados também têm em comum abordar o presente como duradouro, porque mutável, o ser humano que vive da tradição ao futuro como um único tempo. Lembram, aí, Grahame Clark, arqueólogo que ressalta a importância de salvar a tradição, não permitindo que se fossilize. Reverbera essa atitude, sem dúvida, na preocupação ética de Betty Mindlin, ao recolher as narrativas, assim como em Bairon, ao se deter na construção digital de objetos tridimensionais, permitindo ao usuário/ jogador conhecer, por exemplo, a sala de Freud em Viena, sua cadeira (a girar, em uma das brincadeiras de criação), o famoso divã, sua vitrine de objetos.

Vale lembrar que a noção de aventura - e aí se inclui a viagem/navegação pelo tempo e pelo espaço, pelo diverso e pelo idêntico - encontra-se tanto em Terra grávida quanto em Hipermídia. São explorações dos conceitos de cultura e de linguagem, que permitem pronunciar vivencialmente a pluralidade presente em ambos.

$\mathrm{O}$ trabalho de Mindlin é evidentemente vinculado à pluralidade cultural brasileira, cooperando, assim, na construção/transformação da identidade cultural/identidade nacional de que se tratava logo ao início deste artigo. Contudo, vai além, trata do universal, como lembra Gambini (1993:13): “(...) esses contos brasileiros recolhidos no mato mereceriam a atenção de exegetas do nível de Antonio Candido, Joseph Campbell ou Marie Louise von Franz. Quem sabe assim nós brasileiros começaríamos a valorizar aquilo que diz a alma ancestral de nossa terra e teríamos algo que nos enaltecesse para mostrar ao mundo."

Da mesma forma, o trabalho de Bairon é também um produto tipicamente brasileiro, a configurar novas percepções/criações que o Brasil propicia, mas se abre também para o mundo, de onde igualmente tira inspiração. Como afirma Santaela (2000): "Não tenho dúvidas de que este magnífico trabalho será um marco na história da hipermídia não só no Brasil mas também em um contexto internacional, pelo hibridismo denso cuja germinação só a sopa biótica do sincretismo próprio à cultura brasileira poderia propiciar."

Trazem ambos, Mindlin e Bairon, os desafios de uma realidade complexa, da qual muitas vezes a escola e a formação de professores têm estado distantes - a compreensão de como se faz cotidianamente a constituição da identidade cultural e da identidade nacional no Brasil. 
Terra grávida, como quer seu nome, traz dessa complexidade a permanência e o novo, o milenar desconhecido. É, em si, um convite para que o educador repense suas práticas mediante subsídios efetivos, sendo tocado pelas histórias e pelos mitos que trazem a vida de grupos indígenas. Indígenas que, ao serem tratados na escola como têm sido - ou seja, como se fossem, independentemente de seus grupos, homogêneos restos de um passado -, são invizibilizados como parte constituinte deste presente plural e diverso que de fato o Brasil é.

Para Bairon, a complexidade referida significa avançar nas possibilidades tecnológicas sem cair num determinismo maquínico aparentemente aberto, mas sem perspectivas, porque aprisionado na tecnologia como valor em si. Ao invés disso, o que faz é, avançando nas possibilidades hipermidiáticas, repercutir as construções culturais e científicas, reconstruir e ampliar as possibilidades de criação estética e conceitual, de capacidade de perguntar e buscar, capacidades especificamente humanas. Hipermídia é, pois, um convite para a aproximação a um meio que, pela mitificação indevida, é visto por muitos educadores, pelas condições de nosso país, como futuro inacessível, com o que se perde de vista este presente no qual está entre nós, por toda parte, determinando nossa existência, à espera de que tomemos as rédeas desse processo. A reiteração hermenêutica de que "o ser se define pelo entorno", soberano no mapa do labirinto, é o convite à reflexão e o alerta que os educadores não podem deixar de perceber.

\section{NOTAS}

E-mail da autora: rosefish@usp.br

A autora é vice-presidente do Júri Internacional do Prêmio Unesco de Educação para a Paz, Paris e diretora-presidente do Instituto Plural - SP.

1. Ainda em sua fase de trabalho como economista, Betty Mindlin coordenou a publicação de uma coletânea que se tornou um clássico, contando com intelectuais à época - tempos de chumbo - perseguidos pelo governo autoritário, reunidos em torno do Cebrap, logo após sua fundação. Trata-se da obra Planejamento no Brasil, publicada pela editora Perspectiva, em 1970.

2. Ainda estão presentes no trabalho de Mindlin, como referências, Pierre Clastres, Roger Bastide, Berta Ribeiro, entre outros.

3. A referência, aqui, é a idéia de transcriação como presente na tradução/ transcriação de Blanco, de Octávio Paz, por Haroldo de Campos (1986).

4. Em trabalho anterior, Mindlin (1997b) chega a discutir a questão dos direitos autorais e como a equaciona.

5. A autora apresenta os mais profundos e sinceros agradecimentos a Betty Mindlin que lhe possibilitou acesso à carta de Lévi-Strauss, bem como autorizou sua inclusão neste artigo preparado especificamente para esta revista.

6. Professor no Programa de Pós-Graduação em Semiótica da PUC - São Paulo e do Programa de Pós-Graduação em Educação, Arte e História da Cultura da Universidade Presbiteriana Mackenzie.
7. Vale a pena lembrar que Richard Sennett vale-se do conceito hermenêutico de jogo para analisar as relações entre público e privado, trabalho que já foi utilizado para uma reflexão sobre a temática da escola pública e da prática do professor, bem como da equipe escolar (Fischmann, 1994).

8. Em seu trabalho A margem e a linguagem da hipermídia, o título de um dos capítulos é exatamente "História como elo da interdisciplinaridade" (Bairon, s/ data).

9. São citados, a seguir, a título de ilustração, alguns dos conceitos oferecidos à escolha em Hipermídia, por sobre o mapa do labirinto: alteridade, ciência, cultura, cultura material, desejo, espelho, fenômeno, fragmentos, hermenêutica, hipermídia, horizonte, incompletude, jogo, lexia, linearidade, linguagem ordinária, não-dito, oralidade, significante, sujeito, techné, inconsciente, verdade.

10. Ver, por exemplo, Gadamer (1991, parte III).

11. Por exemplo, no jogo da velha em Hipermídia.

12. Já que se trata de unir teoria e prática, foi necessário consultar a Internet para se conhecer a autoria, a saber, Glória Perez, e a data exata da estréia da novela: novembro de 1995 (www.members.tripode.com/ korber/novelas.htm). Agradeço a Érica Sacato Tongu pelo levantamento.

13. Freqüentemente chegam mensagens encaminhadas de terceiros, com comentários do tipo "esse valia a pena", "não gosto desse tipo de coisa, mas neste caso em particular...", até o abertamente ambíguo "se disserem que eu mandei, nego". É interessante também observar que essas mensagens têm certa característica adolescente, como de resto a própria estética geral da Internet, lembrando o estilo "MTV", o que parece se justificar, em particular, pelo fato de que é comum adolescentes serem os responsáveis por páginas, proliferando "webdesigners" extremamente jovens, notícia comum em levantamentos da grande imprensa.

\section{REFERÊNCIAS BIBLIOGRÁFICAS}

BACHELARD, G. A epistemologia. Lisboa, Edições 70, 1984.

BAIRON, S. Multimídia. São Paulo, Global, 1995. s/data. A margem e a linguagem da hipermídia (no prelo), ex. reprogr., (coord.). Hipermídia, psicanálise e história da cultura. Apresentação em hipermídia. São Paulo, produção independente, 2000a. (coord.). "Making of" de Hipermídia, psicanálise e história da cultura. São Paulo/Caxias do Sul, Editora Mackenzie/Educs, 2000b.

BRASIL. Parâmetros Curriculares Nacionais. Brasília, MEC/SEF, 1997. SEF, 1998.

. Parâmetros Curriculares Nacionais. (5ª à $8^{\text {a }}$ série). Brasília, MEC/ 1999.

Referenciais para formação de professores. Brasília, MEC/SEF,

CASTELlS, M. A sociedade em rede. São Paulo, Paz e Terra, 1999.

DICKINSON, E. "Como se o Mar se abrisse". Cinqüenta poemas. Rio de Janeiro/São Paulo, Imago/Alumni, 1999; seleção e tradução de Isa Mara Lando.

FISCHMANN, R. "Escola: espaço de construção da cidadania". Idéias. São Paulo, n.24, SE/FDE, 1994, p.153-167.

"Estratégias de superação da discriminação étnica e religiosa no Brasil”. Direitos humanos no Século XXI. Parte II. Brasília, MRE/Ipri/Funag, 1998, p.959-985 (http://www.mre.gov.br/ipri/SDIREITOSHUMANOS).

GADAMER, H.-G. Verdad y método - Fundamentos de una hermenêutica filosófica. 4a ed. Salamanca, Sígueme, 1991.

GAMBINI, R. "Prefácio". In: MINDLIN, B. e NARRADORES INDÍGENAS Tuparis e tarupás. São Paulo, Brasiliense/Edusp/Iamá, 1993.

MINDLIN, B. e NARRADORES SURUÍ. Vozes da origem - Estórias sem escrita. Narrativas dos índios Suruí de Rondônia. São Paulo, Ática/Iamá, 1996.

MINDLIN, B. e NARRADORES INDÍGENAS. Tuparis e tarupás. São Paulo, Brasiliense/Edusp/Iamá, 1993. 1997a. Moqueca de maridos. Rio de Janeiro, Record/Rosa dos Tempos, Terra grávida. Rio de Janeiro, Record/Rosa dos Tempos, 1999.

MINDLIN, B. Planejamento no Brasil. São Paulo, Perspectiva, 1970. 
"Tradição oral, literatura e escrita: um registro voltado para a educação indígena”. In: D'ANGELIS, W. e VEIGA, J. (orgs.). Leitura e escrita em escolas indígenas - Encontro de educação indígena no $10^{\circ}$ Colel 1995. Campinas/São Paulo, ALB/Mercado de Letras, 1997b, p.53-81.

. "A verdadeira descoberta do Brasil". Pátio - revista pedagógica. Porto Alegre, Artes Médicas, Ano 2, n.6, agosto/outubro 1998, p.12-15.

PAZ, O. e CAMPOS, H. Transblanco. São Paulo, Brasiliense, 1986.

QUEIROZ, M.I.P. “Identidade cultural, identidade nacional no Brasil”. Tempo Social - Revista de Sociologia da USP. São Paulo, v.1, n.1, 1ำ sem. 1989, p.29-46.

SANTAELLA, L. "Prefácio". In: BAIRON, S. (coord.). Hipermídia, psicanálise e história da cultura. Apresentação em hipermídia. São Paulo, produção independente, 2000.
SENNETT, R. O declínio do homem público - As tiranias da intimidade. São Paulo, Companhia das Letras, 1989.

SILVA, A.L. A questão indígena na sala de aula - Subsídios para professores de $1^{o}$ e $2^{2}$ graus. $2^{\mathrm{a}}$ ed. São Paulo, Brasiliense, 1987.

SILVA, A.L. e GRUPIONI, L.D.B. A temática indígena na escola - Novos subsídios para professores de $1^{\circ}$ e $2^{\circ}$ graus. Brasília, MEC/Mari/Unesco, 1995.

SILVA, R.H.D. Professores indígenas: um projeto de autonomia (O movimento dos professores indígenas do Amazonas e Roraima - 1988 a 1993). Tese de doutoramento. São Paulo, Faculdade de Educação da USP, 1997.

TERENA, M. "Promoção dos direitos indígenas: Brasil 500 anos". Direitos humanos no Século XXI. Parte II. Brasília, MRE/Ipri/Funag, 1998, p.875-895 (http://www.mre.gov.br/ipri/SDIREITOSHUMANOS).

WILliAMS, R. Cultura. Rio de Janeiro, Paz e Terra, 1992. 